\title{
Research Paper: Comparison of the Charges of 10 Selected Surgeries in Imam Reza Hospital, Mashhad City, Iran, With Their Official Global Prices
}

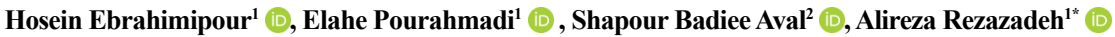 \\ 1. Social Determinants of Health Research Center, Department of Health and Management, School of Health, Mashhad University of Medical Sciences, \\ Mashhad, Iran. \\ 2. Department of Complementary and Chinese Medicine, School of Persian and Complementary Medicine, Mashhad University of Medical Sciences, \\ Mashhad, Iran
}

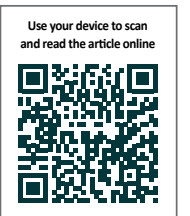

Citation Ebrahimipour H, Pourahmadi E, Badiee Aval Sh, Rezazadeh A. Comparison of the Charges of 10 Selected Surgeries in Imam Reza Hospital, Mashhad City, Iran, With Their Official Global Prices. Journal of Research \& Health. 2020; 10(5):319328. http://dx.doi.org/10.32598/JRH.10.5.1712.1

: http://dx.doi.org/10.32598/JRH.10.5.1712.1

\section{Keywords:}

Health care economics, Hospital charges

\begin{abstract}
A B S T R A C T
Background: This descriptive, analytic study aimed to compare the costs of 10 types of Global Budget Payment System (GBPS) surgery in Imam Reza Hospital, Mashhad City, Iran, in 2016 with the prices in the GBPS.

Methods: From hospital-discharge data and patients' bills, we identified 10 types of GBPS surgeries performed in Imam Reza hospital. The patients were grouped according to the surgical procedures performed in the 10 GBPS category. Data on hospital charges and cost-to-charge ratios were used to assess charges and costs for specific resources, as well as for the hospitalization overall. The researcher received training from the experts in the field of hospital accounting to learn how to determine the charge of GBPS surgeries.

Results: The results showed that in some surgeries such as hysterectomy, natural delivery, C-section, tonsillectomy, hernia repair, and appendectomy, charges of services were higher than their average prices GBPS and in arteriovenous anastomosis surgery, cholecystectomy, tympanoplasty, and thyroidectomy were lower than average prices GBPS. One of the main goals of Iran's Ministry of Health in developing GBPS was to provide a unified framework for managing admission and treatment costs in state-owned hospitals. The obtained data were analyzed by the Wilcoxon signed-rank test and the independent samples $t$ test with 0.05 statistical significance. The results of this study and similar works show that most hospitals have completely neglected this aspect of GBPS.
\end{abstract}

Conclusion: A fact that is reflected in the wide-ranging variations in the charge of GBPS surgeries in different hospitals despite their being paid based on the same rates and guidelines.

\section{* Corresponding Author: Alireza Rezazadeh, MSc.}

Address: Social Determinants of Health Research Center, Department of Health and Management, School of Health, Mashhad University of Medical Sciences, Mashhad, Iran.

Phone: +98 (93) 37955395

E-mail: alireza.Rezazadeh1990@gmail.com 


\section{Introduction}

ospitals are the largest and most expensive operational units of healthcare systems; $\mathbf{H}$ therefore, their efficiency, cost-effectiveness, and ability to offer services at reasonable prices are of great importance for the success of these systems [1]. One of the main challenges of health policymakers is how to set up effective payment and financing mechanisms for health services provided in hospitals as well as smaller health facilities [2]. Today, this issue deserves even more attention as many low- and middle-income countries are working to reduce the costs of their healthcare systems by revising the mechanisms of public insurance, service cost reimbursement, and health budget allocation [3].

In Iran, one of the mechanisms of payment to state-funded health service providers is a flat rate scheme known as the Global Budget Payment System (GBPS). This system has been in effect since 1999 when Iran's Ministry of Health and Medical Education in cooperation with the representatives of insurance companies analyzed 60 of the most common surgical procedures with similar surgical codes and devised a series of price tables based on the average cost of these procedures [4]. In this system, insurance companies are only obligated to pay the amounts listed in the price tables regardless of the expenses incurred by the hospital while performing the surgery [5].

The government's goal in setting up the GBPS was to accelerate the processing and payment of hospital bills by insurance companies, encourage effective resource management in state-funded hospitals in the framework of a plan known as health centers self-administration, and increase patient's satisfaction [4]. At present, the GBPS is used as the payment mechanism for state-funded secondary and tertiary services in Iran $[5,6]$.

In recent years, high inflation and significant currency devaluation in Iran have dramatically raised the price of health service inputs such as medicines, instruments, consumables, etc., but the changes in the price tables of the GBPS have been somewhat lower than the rate of inflation. Therefore, many state-funded hospitals demand a reassessment of the prices of surgeries in the GBPS [4]. In a study conducted in Tehran, it was reported that for all but 7 surgeries (a total of 61 procedures), the costs incurred by the hospital are 3\%-312\% higher than the prices set by the GBPS [7]. In contrast, a study conducted in Hormozgan reports that for $86 \%$ of the surgeries, the charges are lower than the GBPS price rates and that the differences are significant in $91 \%$ of the cases [8].
A large portion of patients admitted to state-funded hospitals fall in the domain of the GBPS. Thus, unrealistically high or low GBPS price rates can have negative impacts on the quality or cost-effectiveness of the services provided in these facilities. When the charge of surgeries is higher than the GBPS prices, hospitals have to absorb the deficit by cutting costs in other areas; a solution that is financially unsustainable and reduces the quality of services. Conversely, when the charges are lower than the GBPS rates, it is the insurers that pay the difference, and this can undermine their payment ability over the long term [7].

In the fee-for-service system, every year insurers spend vast financial and labor resources on the processing of service bills and records produced by hospitals. The GBPS is much more cost-effective for insurance companies, as it reduces the cost of record processing. Although GBPS surgeries are common, since insurers pay a fixed amount for each surgery, they can save a lot of time and resources by avoiding the bureaucracy that is typical for other procedures. This system also allows hospitals to save time, money, and human resources in the processing of accounting records of these surgeries. Despite these benefits, GBPS has several shortcomings, most notably in the mechanism of pricing, which has long been a point of contention between service providers, insurers, and the government, as it has a direct impact on the financial performance of hospitals and insurers as well as patient care quality. Therefore, careful adjustment of the prices of the GBPS to make sure that they match the charges is imperative for preventing financial damage to hospitals and insurance companies.

Imam Reza Hospital is a state-funded hospital located in Mashhad City, Iran. With 900 beds, this facility is the largest hospital under the administrative care of Mashhad University of Medical Sciences and the largest health center in the northeast of Iran. Every year, a wide range of GBPS surgeries are carried out in this hospital. This study aimed to compare the costs of 10 types of GBPS surgeries in Imam Reza Hospital with the prices in the GBPS in 2016.

\section{Methods}

This descriptive cross-sectional study was conducted in Imam Reza Hospital (Mashhad, Northeastern Iran) in 2016. Of all GBPS surgeries performed in this hospital in 2016 (9579 cases), 10 types of surgery (performed in 7231 cases) were selected based on their prevalence and their costs (according to the 2016 GBPS prices approved by the Central Insurance of Iran). The selected surgery types account for $75 \%$ of all GBPS surgeries performed 
in this hospital in 2016 and $81 \%$ of the revenue earned through the GBPS in that year.

The researcher received training from the experts in the field of hospital accounting to learn how to determine the charge of GBPS surgeries. Then, a checklist was designed for gathering data from standard cost items in the hospital bills and patient admissions files. The collected data included the admission information (case number, admission date, insurance type, gender, age, Length of Stay (LOS), hospitalization ward, GBPS code) and the information about the cost of hospital services (laboratory fees, bed-day cost, anesthesia cost, surgeon fee, assistant surgeon fee, operating room cost, nursing cost, cost of operating room medicines and consumables, radiology cost, physiotherapy cost, ultrasound cost, CT scan cost, chemotherapy cost, echocardiography cost, visit fee, counseling fee, cost of other medical treatments, and other expenses). The charges of GBPS surgeries were calculated based on the latest edition of the Iranian relative value scale (2016).

The sample size was determined based on a pilot study, which involved examining four cases for each category (code) of GBPS and computing their costs. These cases were selected randomly based on their file number and from different months to avoid any bias in the selection. After determining the range of cost variations in pilot cases (40 cases), including their means and standard deviations (Table 1), Cochran's sample size formula for finite populations was used to compute the number of samples needed for each category (code). The total sample size for 10 types of GBPS surgery was calculated to 385 .

Next, the medical records of 385 cases were thoroughly reviewed to extract all cost items. These cases were selected by systematic random sampling based on file numbers and from different months of the year. In cases where the medical records of the randomly chosen file number were unavailable, another file number was randomly selected to serve as a replacement. These measures were taken to ensure random selection based on a uniform distribution to avoid case selection bias in the results. To prevent errors in data collection, the process of data collection, and the information extracted from the records were monitored by an experienced revenue accountant.

It should be noted that purchasing power against the dollar is an economic method for determining the relative value of the two currencies. Given the varying value of different currencies and the fact that the price of a product varies according to economic conditions in different countries, and then a special index is required to compare between different countries and services. So, according to statistics extracted from WHO and World Bank websites in 2016, the equivalent of one PPPUS\$ (\$1= IRR35000) was calculated in Iranian Rial and for calculations, in the following study, this coefficient was used to change Iranian Rial to PPPUS\$ [9].

Table 1. Mean \pm SD cost of pilot cases of 10 selected common surgeries in Imam Reza Hospital PPPUS\$

\begin{tabular}{|c|c|c|c|c|}
\hline Final Sample Size & $\begin{array}{l}\text { Standard Deviations } \\
\text { Cost of Pilot Cases }\end{array}$ & $\begin{array}{c}\text { Mean Cost of Pilot } \\
\text { Cases }\end{array}$ & Surgery & National GBPS Code \\
\hline 91 & 74 & 254 & Inguinal hernia & 990135 \\
\hline 54 & 66 & 502 & Hysterectomy & 990225 \\
\hline 30 & 31 & 211 & Tonsillectomy & 990100 \\
\hline 30 & 74 & 505 & Cholecystectomy & 990130 \\
\hline 30 & 119 & 442 & C-section & 990250 \\
\hline 30 & 21 & 227 & $\begin{array}{c}\text { Arteriovenous anasto- } \\
\text { mosis surgery }\end{array}$ & 990340 \\
\hline 30 & 25 & 386 & Appendectomy & 990120 \\
\hline 30 & 49 & 305 & Natural delivery & 990180 \\
\hline 30 & 13 & 464 & Thyroidectomy & 990270 \\
\hline 30 & 56 & 377 & Tympanoplasty & 990315 \\
\hline 385 & & & & Total \\
\hline
\end{tabular}


Data analysis was performed using descriptive statistics (frequency, mean, standard deviation). Inferential statistics were also used to examine the relationships between variables. When our interest is the between-group comparison, the 2-sample t test would be applied. When normality assumptions are not satisfied for any one or both of the groups, the equivalent nonparametric Wilcoxon signed-rank test should be applied. For normally distributed data, the independent samples t test was used. All statistical analyses were performed in SPSS V. 16 at the 0.05 significance level.

\section{Results}

Overall, 385 cases of this study had a total charge of 132673 dollars and their total GBPS price was 141799 dollars. The comparison of the charges of 10 selected common surgeries in Imam Reza Hospital with their official prices in Iran's GBPS in 2016. The average charge of services included in the list of GBPS surgeries was 345.50 dollars, which is 35.90 dollars higher than the average price of these surgeries in the GBPS, that is, 381.41 dollars. This means that, on average, the hospital earns 35.90 dollars profit per operation (Table 2).

Table 3 shows the share of each cost item in the total charge (the amount spent by the hospital for the items recorded in the patient file) and the income from the operation (the amount received by the hospital from the insurer). According to Table 3, for the selected 10 types of GBPS surgery performed at Imam Reza Hospital in 2016, the cost items with the largest shares of the charges are surgeon fee, hoteling cost, consumables cost, operating room cost, and medicine cost, which together account for $81 \%$ of the total charge. The greatest components of the payments received from the GBPS were surgeon fee, hoteling cost, operating room cost, consumables cost, and anesthesia cost, which accounted for $87 \%$ of the total amount received.

Table 2. Comparison of the charges of 10 selected common surgeries in Imam Reza Hospital with their official prices

\begin{tabular}{|c|c|c|c|c|c|c|c|c|c|}
\hline $\begin{array}{l}\text { Name of } \\
\text { Surgery }\end{array}$ & $\begin{array}{c}\text { National } \\
\text { GBPS } \\
\text { Code }\end{array}$ & $\begin{array}{c}\text { GBPS } \\
\text { Price in } \\
2016\end{array}$ & Mean $\pm S D$ & $\begin{array}{l}\text { Mean of } \\
\text { (GBPS } \\
\text { Prices- } \\
\text { Charges) }\end{array}$ & $\begin{array}{c}\text { Sample } \\
\text { Size }\end{array}$ & $\begin{array}{c}\text { Number } \\
\text { of Surger- } \\
\text { ies }\end{array}$ & $\begin{array}{l}\text { P, t-test, } \\
\text { Wilcoxon }\end{array}$ & $\begin{array}{l}\text { Mean } \\
\text { of the } \\
\text { Length of } \\
\text { Stay } \\
\text { (GBPS) }\end{array}$ & $\begin{array}{c}\text { Mean } \\
\text { of the } \\
\text { Length of } \\
\text { Stay } \\
\text { (Patients) }\end{array}$ \\
\hline $\begin{array}{c}\text { Arterio- } \\
\text { venous } \\
\text { anastomo- } \\
\text { sis surgery }\end{array}$ & 990340 & 419.71 & $27.42 \pm 225.51$ & 194.20 & 30 & 388 & $0.001^{*}$ & 5 & 0.2 \\
\hline $\begin{array}{l}\text { Cholecys- } \\
\text { tectomy }\end{array}$ & 990130 & 560.20 & $76.61 \pm 425.79$ & 134.41 & 30 & 678 & $0.003^{*}$ & 5.9 & 2.5 \\
\hline $\begin{array}{l}\text { Tympano- } \\
\text { plasty }\end{array}$ & 990315 & 455 & $36.42 \pm 334.58$ & 120.42 & 30 & 228 & $0.003^{* *}$ & 3.3 & 1.1 \\
\hline $\begin{array}{c}\text { Thyroidec- } \\
\text { tomy }\end{array}$ & 990270 & 498.63 & $31.63 \pm 457.99$ & 40.64 & 30 & 102 & $0.002 *$ & 4.5 & 2.7 \\
\hline $\begin{array}{l}\text { Appendec- } \\
\text { tomy }\end{array}$ & 990120 & 336.43 & $42.40 \pm 339.65$ & $-3.22 * * *$ & 30 & 379 & $0.68 * *$ & 3.2 & 1.9 \\
\hline $\begin{array}{l}\text { Hernia } \\
\text { repair }\end{array}$ & 990135 & 262.77 & $54.13 \pm 268.85$ & $-6.08 * * *$ & 91 & 245 & $0.29 * *$ & 2.45 & 1.6 \\
\hline $\begin{array}{l}\text { Tonsillec- } \\
\text { tomy }\end{array}$ & 990100 & 190.91 & $17.06 \pm 207.93$ & $-17.02 * * *$ & 30 & 265 & $0.001^{* *}$ & 1.6 & 1 \\
\hline C-section & 990250 & 356.86 & $37.36 \pm 381.14$ & $-24.28 * * *$ & 30 & 2429 & $0.001 * *$ & 2.8 & 2 \\
\hline $\begin{array}{l}\text { Natural } \\
\text { delivery }\end{array}$ & 990180 & 260.71 & $36.10 \pm 287.65$ & $-26.93 * * *$ & 30 & 2393 & $0.002 * *$ & 1.4 & 1.1 \\
\hline $\begin{array}{l}\text { Hysterec- } \\
\text { tomy }\end{array}$ & 990225 & 472.83 & $94.19 \pm 525.94$ & $-53.11 * * *$ & 54 & 124 & $0.004^{*}$ & 4.7 & 3.1 \\
\hline
\end{tabular}

* Normality assumption was not satisfied (Wilcoxon test was used).

** Normality assumption was satisfied (Independent Samples t-test was used)

*** These items are GBPS prices < charges. 
Table 3. The share of each cost item in the total charges and the income from the operation

\begin{tabular}{|c|c|c|}
\hline \multirow{2}{*}{ Cost Items } & \multicolumn{2}{|c|}{$\%$} \\
\hline & Share of Total GBPS Income & Share of Total Charges \\
\hline Surgeon fee & 31.9 & 31.4 \\
\hline Hoteling cost & 24.9 & 14.7 \\
\hline Consumables cost & 9.8 & 14.7 \\
\hline Operating room cost & 12.8 & 12.6 \\
\hline Medicine cost & 4.2 & 8 \\
\hline Anesthesia cost & 8.1 & 7.7 \\
\hline Laboratory fee & 0.9 & 3.7 \\
\hline Doctor visit & 3.5 & 3.6 \\
\hline Assistant surgery fee & 0.8 & 1.4 \\
\hline Nursing cost & 1.6 & 0.9 \\
\hline Pathology & 0.3 & 0.5 \\
\hline Other costs & 0.2 & 0.5 \\
\hline Counseling fee & 0.5 & 0.3 \\
\hline Sonography & 0.1 & 0.1 \\
\hline Electrocardiography & 0.1 & 0.1 \\
\hline Radiology cost & 0.3 & 0.04 \\
\hline Total & 100 & 100 \\
\hline
\end{tabular}

IRA

The cost items that share of total GBPS income are more than share of total charges are hoteling cost, surgeon fee, nursing cost, anesthesia cost, operating room cost, radiology cost, and counseling fee, and the items that share of total GBPS income are more than share of total charges are consumables cost, medicine cost, laboratory fee, and assistant surgery fee.

\section{Discussion}

This study aimed to compare the Imam Reza Hospital's revenues from common GBPS surgeries with their actual cost for this hospital.

The results show that, given the difference between the price of surgeries in the GBPS and their charges, in 2016, the hospital charged higher than total GBPS income whenever it performed hysterectomy, natural delivery, C-section, tonsillectomy, hernia repair, and ap- pendectomy. They earned a profit from arteriovenous anastomosis surgery, cholecystectomy, tympanoplasty, and thyroidectomy. For eight of these surgeries, the difference between the GBPS rates and the charge is statistically significant $(\mathrm{P}<0.05)$, and the only surgeries for which this difference is insignificant were appendectomy $(\mathrm{P}=0.68)$ and hernia repair $(\mathrm{P}=0.29)$.

Similar to this study, other studies conducted in different hospitals in Iran have found significant differences between the prices listed in the GBPS and the charge of covered surgeries, which in some cases are in favor of hospitals and others are in favor of insurers [4, 7, 8, 10-12]. This difference can be attributed to different reasons. However, since other studies have only compared the total cost of surgeries with their total GBPS price without reporting on the cost items that cause the price differences, they provide little insight into the root causes of these discrepancies. 
For all surgery types studied in this work, the actual average LOS was shorter than the average LOS considered in the GBPS. In other words, in 2016, the cost incurred by the hospital for surgery-related hoteling has been lower than the amount it has received for this service from insurers. The highest average difference between the average LOS approved in the GBPS and the average LOS in the examined cases is related to arteriovenous anastomosis surgery (4.8 days), cholecystectomy (3.4 days), tympanoplasty (2.2 days), and thyroidectomy (1.8 days), which is one of the reasons why these surgeries are so profitable for the hospital.

Similar studies have also reported that the actual average LOS is often shorter than the LOS for which insurers are obligated to pay. For example, in a study by Hosseini et al., the average LOS was 1.3 days for $\mathrm{C}$-section, 1.3 days for a natural delivery, 1.1 days for hernia repair, 1.2 days for appendectomy, 1.5 days for cholecystectomy, 1.4 days for hysterectomy, and 3.1 days for thyroidectomy [8]. In a study by Madani, the average LOS was 1.8 days for C-section, 1.9 days for appendectomy, and 1.7 days for hernia repair [11], which are all shorter than the average LOS considered in the GBPS.

Given the shortage of medical centers, personnel, facilities, and equipment in Iran and the rising costs of healthcare services, optimizing the LOS and the factors that affect it is of great importance for making the most of existing capacities. The suboptimal use of already insufficient resources is a frequent issue in Iranian hospitals, which hospital managers can partly resolve by reducing the average LOS [13]. Reducing the LOS can be expected to increase the admission capacity of the hospital and reduce waiting times before receiving services [14].

However, a shorter LOS increases the potential for requiring more services as well as the average cost of services per day. In other words, short stays have an adverse impact on health outcomes and increase the probability of re-admission, which undermines the patient's comfort and recovery time. If our goal in reducing the average LOS is to just increase the number of new admissions, it is likely to lead to increased cost instead of cost-saving [15].

By comparing the payments made by insurers for medicine and consumables in the GBPS with their average actual costs for the hospital, it was found that the charge of medicine for arteriovenous anastomosis surgery and the charge of consumables for tympanoplasty are lower than the rates considered in the GBPS. For other surgeries, however, the charge of medicine and consumables is higher than the said rates.
Multiple studies have shown that the cost of medicine and consumables makes up a significant portion of the total cost of surgical procedures. In a study in Yazd, the cost of medicine and consumables was found to account for $35 \%$ of the total cost of an appendectomy [16]. In a study by Ebrahimipour on the Heart Department of Imam Reza Hospital in Mashhad, 53\% of the total cost of the department was related to medicine and consumables [17]. In other studies, this figure was reported to be $23 \%$ for the ICU of Shafa Hospital in Kerman [16], 49\% for the Dialysis Department of Shahid Sadoughi Hospital in Yazd [18]. In the studies of Nagrini [19], and Nikpajooh et al. [20], these ratios were $22 \%$ and $16.61 \%$, respectively.

Naturally, irrational medicine prescription can have adverse consequences such as patient dissatisfaction, prolongation and exacerbation of diseases, dangerous side effects, and increased medical costs for individuals as well as government, and most importantly for Iran, exacerbation of the drug shortage problem [21]. The findings of the present study show that medicine and consumables have a huge impact on the payments made through GBPS, and on average, account for $22.7 \%$ of any bill exchanged in this framework. For 9 out of 10 surgery types studied in this work, the charge of medicine and consumables was much higher than the GBPS rate. This finding can be explained in two ways:

1. The hospital has failed to manage its medicine and consumable supplies efficiently, in which case, there is a need for more precise planning in this regard, the implementation of medical prescription and use standards such as Medication Management and Use (MMU) based on Joint Commission International (JCI) accreditation, and also a concerted effort to promote the optimal use of medical supplies.

2. The prices considered in GBPS for medicine and consumables are unrealistically low. In which case, GBPS rates should be modified to address the issue and eliminate the hospital deficit due to these cost items.

This study found that, on average, surgeon fees and anesthesia costs constitute about $40 \%$ of the total charge of GBPS surgeries. Studies conducted in different hospitals in Iran have also shown that in most cases personnel costs make up the largest portion of hospital service cost. For example, it has been reported that the personnel costs of the Radiology Department at Shafa Hospital in Kerman, Neurosurgery Department at Imam Khomeini Hospital in Tehran, Radiology Department at Golestan Hospital in Ahvaz, and Radiology Department at Amiralam Hospital in Tehran constitute respectively 55.7\%, 49\%, 43\%, 
and $66.19 \%$ of the total cost of these departments. Typically, a high percentage of the money spent on the personnel goes to physicians [16, 20-23]. The physicians' share of personnel expenses in Iran has increased even more after the implementation of the healthcare system transformation plan and the introduction of the latest national relative value scale.

\section{Conclusion}

One of the main goals of Iran's Ministry of Health in developing GBPS was to provide a unified framework for managing admission and treatment costs in state-owned hospitals. The results of this study and similar works show that most hospitals have completely neglected this aspect of GBPS. A fact that is reflected in the wide-ranging variations in the charge of GBPS surgeries in different hospitals despite their being paid based on the same rates and guidelines. This issue suggests the need for a revision in GBPS to make the pricing more transparent and realistic with a better balance between the interests of insurers and hospitals. For example, there must be clear answers to the questions that exactly how GBPS surgeries are priced in the first place, and what is the rationale and metric behind yearly increases in prices.

In GBPS, hospitals are divided into four grades based on their accreditation, and prices are adjusted to the grade with grade 1 hospitals having the highest rates. However, it has been neglected that two hospitals with the same accreditation can differ in terms of the number of beds, occupancy rates, the size of personnel, being a teaching or non-teaching center, being general-purpose or specialized, and so on, and these differences can greatly affect the costs of operations.

Considering the above issues, revision of GBPS seems necessary for protecting insurers and service providers (Hospitals) against financial instability and, more importantly protecting patients against declining service quality. According to the findings of this research, for four surgical procedures, namely arteriovenous anastomosis surgery, cholecystectomy, tympanoplasty, and thyroidectomy, the charges of surgery in Imam Reza Hospital are significantly lower than the GBPS prices, which is mostly because of the income generated through hoteling, surgeon, and operating room fees.

Although hospitals have some degree of control over expenditures on medicine and consumables (unlike surgeon fee and anesthesia cost, over which they do not have much control) in many cases, the charges of these items in the studied hospital were higher than the payment re- ceived through the GBPS. Therefore, this hospital needs to employ stronger management practices to reduce the consumption of medicine and consumables. In the end, we present the following suggestions based on our findings:

- It is imperative to meticulously record all the cost items of GBPS surgeries in the Hospital Information System (HIS) to allow administrators and planners at the university level as well as the supreme insurance council to thoroughly and rigorously assess the charge of these cases, compare them with the price lists of GBPS.

- It is recommended to perform focused research on the reasons behind the difference between the actual average LOS and the standard average LOS for different diagnoses as a basis for taking corrective action.

- Hospital managers are recommended to set up training programs for hospital staff regarding the specific detail of GBPS surgeries since many of the hospital personnel seem to lack sufficient information about this topic and cannot tell the differences between GBPS and non-GBPS operations in terms of billing and payment.

- For the services and operations that require expensive drugs and consumables or large amounts of lowcost items, insurers should add a proportionate bonus to the GBPS payment to eliminate the hospital deficit due to these cost items.

- For the candidates of GBPS surgeries who have a prolonged LOS and therefore unreasonably high hoteling costs, the expenses due to staying longer than a threshold should be added independently to the GBPS payment.

- It is recommended to sensitize hospitals to the costs of GBPS surgeries and especially the expenditures on medicines and consumables and at the same revise the price lists of GBPS to ensure that the system remains reasonably cost-effective without straining hospital finances.

\section{Ethical Considerations}

\section{Compliance with ethical guidelines}

This research was approved by the Ethics Committee of Mashhad University of Medical Sciences, Iran (Code: IR.MUMS.REC.1395.288).

\section{Funding}

The present paper was extracted from the MSc thesis of the fourth (correspond) author, Department of Health 
and Management Faculty of Health, Mashhad University of Medical Sciences (Code: 940399)

\section{Authors' contributions}

Conceptualization, design: Hosein Ebrahimipour; Data collection, manuscript preparation: Alireza Rezazadeh; Drafting the manuscript: Elahe Pourahmadi; Data analysis, data interpretation: Elahe Pourahmadi, Alireza Rezazadeh; Critical revision: Shapour Badiei Aval, Hosein Ebrahimipour.

\section{Conflict of interest}

The authors declared no conflict of interest.

\section{Acknowledgments:}

The authors would like to thank to Mashhad University of Medical Sciences and Imam Reza Hospital for supporting this study.

\section{References}

[1] Akbari F, Arab M, Keshavarz K, Dadashi A. [Technical efficiency analyses in hospitals of Tabriz University of Medical Sciences (Persian)]. J Hosp. 2012; 11(2):65-76. http://jhosp. tums.ac.ir/article-1-29-fa.html

[2] Ghiasvand H, Hadian M, Maleki MR, Shabaninejad H. [Determinants of catastrophic medical payments in hospitals affiliated to Iran University of Medical Sciences 2009 (Persian)]. Hakim Res J. 2010; 13(3):145-54. https://www.sid.ir/en/Journal/ViewPaper.aspx?ID=192602

[3] Lagomarsino G, Garabrant A, Adyas A, Muga R, Otoo N. Moving towards universal health coverage: Health insurance reforms in nine developing countries in Africa and Asia. Lancet. 2012; 380(9845):933-43. [DOI:10.1016/S01406736(12)61147-7] [PMID]

[4] Gholamzadeh Nikjoo R, Dadgar E, Jannati A, Hosseini Asl $\mathrm{M}$, Salek Z. [Comparison of global and actual cost of kidney transplant in Imam Reza hospital, Tabriz (Persian)]. Hakim Res J. 2014; 17(1):22-8. http:/ /hakim.hbi.ir/article-1-1242-fa.html

[5] Marjani AB, Khademi Z. [Comparative study of general (global) surgery procedures costs in proprietary hospitals of social security organization (Persian)]. J Account Knowl Manag Audit. 2012; 1(1):33-42. http://jmaak.srbiau.ac.ir/article_7308.html

[6] Arab M, Zeraati H, Ravangard R, Gholinejad A, Rasooli A. [Comparing global-operations reimbursements with their actual costs in the cancer institute, Tehran (Persian)]. J Sch Public Health Inst Public Health Res. 2008; 6(2):59-66. http:/ / sjsph.tums.ac.ir/article-1-145-fa.html

[7] Chatruz A, Javadinasab H, Amini MK, Biglar M, Goudarzi $\mathrm{N}$, Zarei J. [A comparison of the cost of global surgery bills with approved tariffs in hospitals affiliated to Tehran Univer- sity of Medical Sciences (Persian)]. J Payavard Salamat. 2015 9(1):67-80. http:/ / payavard.tums.ac.ir/article-1-5667-fa.htm

[8] Hosseini-Eshpela R, Khorramy F, Baniasadi T, Azarmehr N, Mohammady F, Hayavy Haghighi MH, et al. [The comparison of the cost of patient records in a global system with corresponding retrospective reimbursement system: A case study in Iran (Persian)]. J Mod Med Inf Sci. 2015; 1(1):65-74. http:/ / jmis.hums.ac.ir/article-1-25-fa.html

[9] Kavosi Z, Jafari A, Keshtkaran V, Pourahmadi E. Estimating willingness to pay for an improved service delivery to patients referring Namazi Hospital chemical therapy ward in Iran using contingent valuation. Asian Pac J Cancer Prev. 2018; 19(7):1817-23. [DOI:10.22034/APJCP.2018.19.7.1817] [PMID] [PMCID]

[10] Pirzadeh A, Amani F. [Estimate total costs for tonsil surgery in Imam and Fatemi Hospitals in Ardabil City and compare with global cost of insurance organization (Persian)] [Internet]. 2011 [Updated 2015 February 16]. Available from http://eprints.arums.ac.ir/3224/

[11] Madani SM, Taji M. [Total cost of selected global surgeries and comparison with accepted fee in Amin Hospital in Isfahan city (Persian)]. Homaye Salamat. 2011; 7(3):6-9. https:// www.magiran.com/paper/854124

[12] Omrani Khoo H. [Economic evaluation of the global reimbursement system and comparison with Karaneh system in hospitals in Boshehr University of Medical Sciences 2001 (Persian)] [MSc. thesis]. Tehran: Iran University of Medical Sciences; 2002. http:/ / centlib.iums.ac.ir:8800/site/catalogue/92174

[13] Nasiripour AA, Riahi L, Gholami Pour MA. [The effect of duration of full-time specialists in obstetrics and gynecology department of the social security hospital, Yazd, 2008 (Persian)]. J Med Counc Iran. 2010; 28(2):169-75. http://jmciri.ir/ article-1-1381-fa.html

[14] Kermani B, Gharsi M, Ghanbari B, Sarabi Asiabar A, Atefi Manesh P, Baniasadi A, et al. [The relationship between the levels of patient care and length of stay in hospital (Persian)] Shefaye Khatam. 2015; 3(S1):32-40. [DOI:10.18869/acadpub. shefa.3.3.32]

[15] Pouragha B. [The average length of stay in the OECD member states (Persian)]. J Hosp. 2007; 7(1-2):30-2. https://jhosp. tums.ac.ir/article-1-5035-fa.html

[16] Zarekhormizi E, Moeen-al-din M, Nayebzadeh Sh. [Cost price estimation of appendix surgery in Yazd Shahid Sadoughi Hospital using activity-based costing in 2011 (Persian)]. J Toloo-e-behdasht. 2015; 13(6):113-26. http://tbj.ssu.ac.ir/ article-1-1379-fa.html

[17] Ebrahimipour H, Rezazadeh AR, Olyani S, Khorsand Vakilzadeh A, Fazaeli S, Jafari M, et al. [Iran's health system evolution and tariff change on cardiovascular ward performance of a big teaching hospital (Persian)]. Payesh. 2017; 16(2):150-8 $\mathrm{http}: / /$ payeshjournal.ir/article-1-112-fa.html

[18] Mohammadi Y, Baghestani E, Bahrami MA, Entezarian Ardekani S, Ahmadi Tehrani Gh. [Calculating the cost price of dialysis in Shahid Sadoughi Hospital using activity based costing: Yazd, 2011 (Persian)]. J Health Account. 2012; 1(1):7384. http://jha.sums.ac.ir/article_16588.html

[19] Negrini D, Kettle A, Sheppard L, Mills GH, Edbrooke DL. The cost of a hospital ward in Europe: Is there a methodology avail- 
able to accurately measure the costs? J Health Organ Manag. 2004; 18(3):195-206. [DOI:10.1108/14777260410548437] [PMID]

[20] Nikpajouh A, Shariati B, Soheili S. [The costs of the radiology ward by step-down method in Amir Alam Hospital, Tehran, Iran (Persian)]. Payesh. 2009; 8(3):235-44. http:// payeshjournal.ir/article-1-608-en.html

[21] Picón-Camacho SM, Marcos-Lopez M, Bron JE, Shinn AP. An assessment of the use of drug and non-drug interventions in the treatment of Ichthyophthirius multifiliis Fouquet, 1876, a protozoan parasite of freshwater fish. Parasitology. 2012; 139(2):149-90. [DOI:10.1017/S0031182011001867] [PMID]

[22] Saber Mahani A, Barouni M, Bahrami MA, Goodarzi GR, Sheikhgholami S, Ebrahimipour Z, et al. [Cost price estimation of radiology services in Shafa Hospital, Kerman, 2010 (Persian)]. J Toloo-e-behdasht. 2011; 10(1):50-61. https:// www.sid.ir/fa/journal/ViewPaper.aspx?id=151953

[23] Torabi A, Keshavarz Kh, Najafpour Zh, Mohamadi E. [Computing cost price by using Activity Based Costing $(\mathrm{ABC})$ method in radiology ward of Golestan Hospital in Ahvaz University of Medical Sciences in 2009 (Persian)]. J Hosp. 2011; 10(2):38-49. http://jhosp.tums.ac.ir/article-1-60-fa.html 
This Page Intentionally Left Blank 